\title{
THE USE OF BIOCERAMICS IN ENDODONTICS - LITERATURE REVIEW
}

\author{
STEFAN JITARU ${ }^{1}$, IOANA HODISAN ${ }^{1}$, LUCIA TIMIS ${ }^{1}$, \\ ANAMARIA LUCIAN ${ }^{1}$, MARIUS BUD ${ }^{2}$
}

\author{
${ }^{1}$ Department of Chemistry, Babes-Bolyai University, Cluj-Napoca, Romania \\ ${ }^{2}$ Department of Odontology, Iuliu Hatieganu University of Medicine and \\ Pharmacy, Cluj-Napoca, Romania
}

\begin{abstract}
Background and aim. Bioceramics are ceramic compounds obtained both in situ and in vivo, by various chemical processes. Bioceramics exhibit excellent biocompatibility due to their similarity with biological materials, like hydroxyapatite. Bioceramics and multi-substituted hydroxyapatite or similar compounds have the ability to induce a regenerative response in the organism.

The aim of this paper is to make a literature review on the main bioceramic materials currently used in endodontics and on their specific characteristics.

Methods. We conducted a search in the international databases (PubMed), to identify publications in the last 10 years, using the following key words: "bioceramics endodontics", "bioceramic endodontic cement", "bioceramic sealer" and "direct pulp capping bioceramic".

Results. Commonly used endodontic sealers (e.g., containing zinc oxide, calcium hydroxide and a resin) have a long tradition in scientific research and clinical use in endodontics. For specific cases, like root resorptions, perforations, apexification, and retrograde fillings, new biocompatible materials were developed in order to improve the clinical outcome: ProRooT MTA (Dentsply Company,Germany); Biodentine (Septodont, France); Endosequence BC sealer (Brassler, SUA); Bioaggregate (IBC, Canada); Generex A (Dentsply Tulsa Dental Specialties, USA).

Conclusion. The studies are generally in favor of bioceramic materials even if there are not many products available on the market for endodontic use. As more products are launched and more research is performed regarding these materials, we will provide more reliable data on clinical outcome.
\end{abstract}

Keywords: bioceramics, biodentine, endodontics

\section{Introduction}

Bioceramics are biocompatible ceramic compounds obtained both in situ and in vivo, by various chemical processes. Bioceramics exhibit excellent biocompatibility properties due to their similarity with biological hydroxyapatite. Bioceramics produce, during the hydration

Manuscript received: 17.11.2015

Received in revised form: 21.12.2015

Accepted: 15.01.2016

Address for correspondence: mariusbud@mbdental.ro process, different compounds, e.g. hydroxyapatites, with the ability to induce a regenerative response in the human body. When placed in contact with the bone, mineral hydroxyapatite has an osteoconductive efect, leading to the bone formation at the interface. There is an intrinsic osteoinductive capacity of the bioceramics, because of their documented ability to absorb osteoinductive substances if there is a bone healing process nearby [1].

Bioceramics have the quality to be biocompatible and also to provide antibacterial properties. The latter occur 
as a result of precipitation in situ after the material's setting time, a phenomenon that leads to bacteria sequestration. Bioceramics form porous powders containing nanocrystals with diameters of 1-3 nm, which prevent bacterial adhesion [2]. Sometimes, fluoride ions are constituents of apatite crystals, and the resulted nanomaterial has antibacterial properties. In addition, bioceramics may be combined with synthetic hydroxyapatite [3].

Even though the advantages of these materials have contributed to their rapid spread in the dental field, nowadays, they are not widely used, and commercially available products on the market are not yet known by many dentists.

The aim of this paper is to perform a literature review on the main bioceramic materials currently used in endodontics and on their specific characteristics.

\section{Some bioceramic materials used in endodontics}

We conducted a search in the international database (PubMed), to identify publications in the last 10 years, using the following key words: "bioceramics endodontics", "bioceramic endodontic cement", "bioceramic sealer" and "direct pulp capping bioceramic".

Commonly used endodontic sealers (e.g., containing zinc oxide, calcium hydroxide and resin) have a long tradition in scientific research and clinical use in endodontics. For specific cases, like root resorptions, perforations, apexification, and retrograde fillings, new biocompatible materials were developed in order to improve the clinical outcome: ProRooT MTA (Dentsply Company,Germany); Biodentine (Septodont, France); Endosequence BC sealer (Brassler, SUA); Bioaggregate (IBC, Canada); Generex A
(Dentsply Tulsa Dental Specialties, USA).

\section{MTA Cement}

The first bioceramic material successfully used in endodontics was the MTA cement (Mineral Trioxide Aggregate), developed based on Portland cement, in the Loma Linda University - California, in the early 90's. It was developed as a retrograde filling material and also for perforations closing (Figure 1).

Portland cement and MTA show comparable composition, physical and chemical properties. Portland cement, used in the construction industry, contains tricalcium silicate (3CaO-SiO2), dicalcium silicate $(2 \mathrm{CaO} \cdot \mathrm{SiO} 2)$, tricalcium aluminate $(3 \mathrm{CaO} \cdot \mathrm{Al} 2 \mathrm{O} 3)$ and calcium sulphate (2CaSO4.H2O) [4]. In addition, MTA contains bismuth oxide, an insoluble substance added to the MTA to confer radiopacity [5].

There are studies which have examined the radiological opacity of Portland cement (Votoran ${ }^{\circledR}$, São Paulo, SP, Brazil ) compared with two MTA cements (ProRoot тм MTA; Dentsply/Tulsa Dental, Tulsa , OK, USA) and MTA - Angelus ${ }^{\circledR}$ (Indústria de Produtos Ltda odontological Angelus Londrina, PR, Brazil) concluding that ProRoot MTA presented a higher percentage of bismuth oxide (average 9.2\%) than MTA - Angelus [6]. Several studies have examined the MTA compared with Portland cement used in construction, in view of physical and chemical similarities of these two materials $[7,8]$. Portland cement shows good adhesion to dentin and a good antimicrobial activity [9]. Considering their similar composition, the use of Portland cement can be a less expensive alternative to MTA.

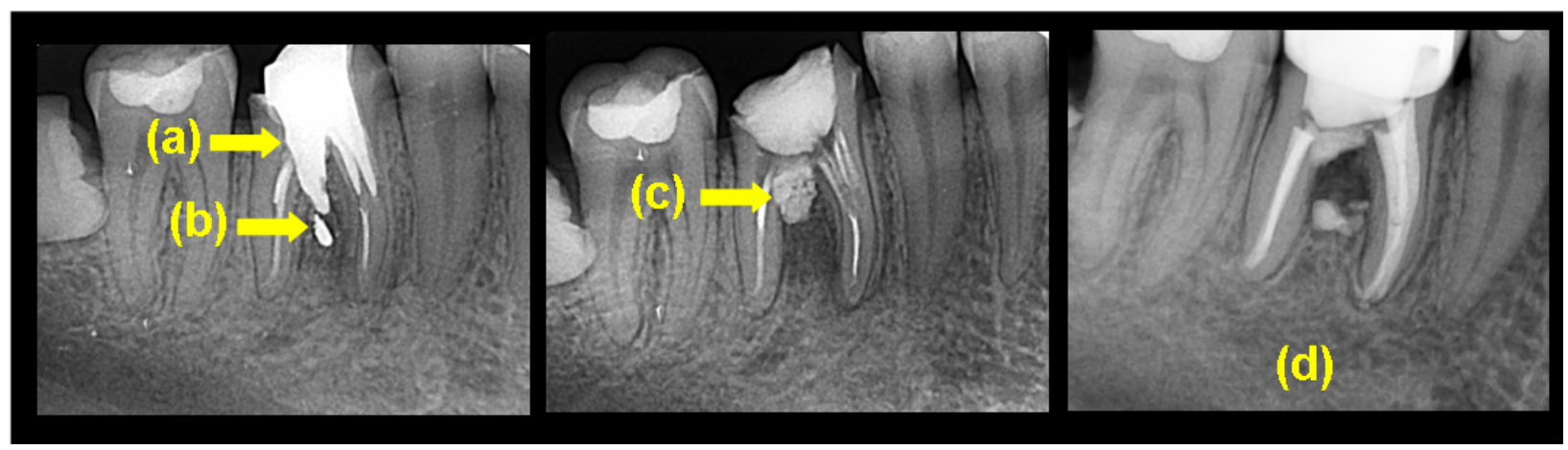

Figure 1. Root perforation repaired with MTA. a) Iatrogenic perforation with metal post in furcation area; b) A segment of the old metal post pushed down in the periodontal space before luting the new metal post; c) Bone defect filled with collagen sponge after removal of both metal posts; perforation closed with MTA (Angelus, Brazil); d)1 year follow up.

MTA cement is calcium silicate cement, consisting of tricalcium silicate, dicalcium silicate and tricalcium aluminate. The radiopaque compound is bismuth oxide. The material comes in two forms, gray and white. In the first form gray color is given by iron ions, which were removed to obtain the white form [10].

MTA's setting reaction is by hydration, obtaining hydrated calcium silicate and calcium hydroxide which is released over time. MTA's biological integration is due to the ions of $\mathrm{Ca}$, which form hydroxyapatite in contact with phosphate ions present in body [1].

The antibacterial role of the MTA cement seems to be due to the release of calcium hydroxide, which explains the similar action with the calcium hydroxide pastes. In addition, it shows a strong alkaline $\mathrm{pH}$, with antibacterial effect $[1,10,11]$. There are techniques described for the use of 
MTA sealer, such as "capillary condensation" technique [12]. Endosequence sealer and paste for retrograde filling and perforation repair

Endosequence BC sealer (Brasseler USA) is another calcium silicate material highly radiopaque, no shrinkage, hydrophilic, forming hydroxyapatite upon setting. The setting reaction is also a hydration reaction. It contains monocalcium phosphate which is responsible for hydroxyapatite formation in situ. Endosequence contains zirconium oxide and tantalum oxide as radiopaque fillers $[11,13]$.

\section{Biodentine}

This material was specifically designed as a "dentin replacement" material by Septodont (France) in 2009. Biodentine contains tricalcium silicate $\left(\mathrm{Ca}_{3} \mathrm{SiO}_{5}\right)$, calcium carbonate, zirconium oxide and calcium chloride. Main indications include the treatment of resorptions, root perforations, pulp capping procedures, apexification, retrograde fillings, and dentin replacement.

\section{BioAggregate}

BioAggregate (Innovative BioCeramix Inc, Canada) is also a calcium silicate cement containing calcium silicate hydrate, calcium hydroxide, hydroxyapatite, silica and tantalum oxide. The product has qualities similar to cement MTA, in terms of marginal sealing, superior adhesion and pulp cells migration [14].

\section{Generex $A$}

Generex A (Dentsply Tulsa Dental Specialties, Tulsa, OK, USA) is a calcium silicate based material that has some similarities to MTA but is mixed with unique gels instead of water. It contains calcium silicate, special gels, hydroxyapatite. It is designed for retrograde fillings and perforation repair. It is considered to have superior resistance to washing, compressive strength and good radiopacity [15].

\section{Some characteristics of bioceramics used in endodontics \\ Microleakage}

Endodontic cements and sealants ensure a tight seal to root dentin in order to prevent micro infiltration. Certain conditions, including perfectly dry canals, are required to achieve good adhesion. In some cases, these may be difficult to obtain clinically. Studies that compared MTA to other sealers widely used in endodontics led to good results for MTA even if canals were not perfectly dried. Comparing some classic sealers used in endodontics, like AH26, Excite DSC, MTA Fillapex and ZOE paste in dry and wet canals, Ehsan et al. [16] demonstrated that AH26 shows the best seal in dry canals and ZOE paste the weakest seal in humidity conditions. MTA showed good sealing even in wet canals.

For complex endodontic treatment cases, completed in several sessions, the use of intracanal medications such as calcium hydroxide or antibiotics may be decided. This medication should be removed from canal in order to achieve a good endodontic filling. MTA adhesion to dentin may be influenced if the intracanal medication is not completely removed because of complex endodontic morphology, technical deficiencies or lack of equipment. When analyzing the strength of MTA displacement in canals with calcium hydroxide and antibiotic medication, Topçuoğlu et al. found an overall decrease of resistance for both situations [17].

\section{Microbiology}

The long term success of an endodontic treatment depends on a perfect filling of the root canal system and complete removal of endodontic bacteria. Comparing the antimicrobial activity of two endodontic cements (MTA Fillapex and AH 26), Madani et al. conclude that MTA has superior efficiency on Enterococcus faecalis, Escherichia coli, Streptococcus mutans and Candida albicans [18]. Moreover, similar studies show that SealApex (Kerr Company, Germany) shows antibacterial properties but meanwhile there are endodontic sealers with no antibacterial activity (eg. Endorez). MTA and Portland cement have demonstrated no antibacterial activity on E. coli [19].

Even though the antimicrobial activity is an important requirement of an endodontic sealer, most of them have no capacity to provide complete protection. MTA Dentsply, MTA Angelus and Portland cement inhibit the growth of $\mathrm{P}$. aeruginosa while calcium hydroxide was effective against $\mathrm{P}$. aeruginosa and B. fragillis. Under anaerobic conditions these materials have not been proven effective for E. faecalis, and E. coli [15].

\section{Cytotoxicity on periodontal ligament fibroblasts}

Mineral Trioxide Aggregate (MTA), Endosequence Root Repair Material and Biodentine showed different results when fibroblast cell cultures were evaluated at 24 and 48 hours. Even if at the first 24 hours all the materials showed increased cell viability, at 48 hours, there is a slight decrease in cell viability. MTA showed statistically significant increase in the cell viability when compared to Endosequence Root Repair Material and Biodentine [20]. We can conclude that MTA shows better biocompatibility and may be indicated for sealing of communication between periodontal and endodontic space. Analyzing the effect on human endothelial cells ECV 304 line of two brands of MTA (Angelus ${ }^{\circledR}$ - MTA, Pro - Root TM -MTA) and Portland cement, in a comparative study, De Deus et al. showed that after initial high cytotoxic activity, these materials increase cell viability [21]. Bismuth oxide has no negative cellular effects [22].

\section{Direct pulp capping}

The complete removal of infected dentin in deep cavities without endodontic pathology may sometimes lead to openings of the pulp chamber with direct exposure of healthy pulp. In certain conditions, closure of this communication may be performed using calcium hydroxide cement for direct pulp capping. The success of this treatment is evaluated by persistence of pulp vitality. Ten years follow- 
up studies indicate $30 \%$ to $85 \%$ success rate $[23,24]$. MTA is a bioactive material that can be used for direct pulp capping $[25,26]$. It is non-resorbable, may set in wet conditions,

and stimulates dentin hard tissue formation [27]. Reported success rate after direct pulp capping is higher when using MTA instead of calcium hydroxide. In a comparative study, Mente et al. reported $80.5 \%$ success rate of direct pulp capping with MTA and $59 \%$ when using calcium hydroxide at 24-123 months (mean 42 months ) [28].

\section{Conclusion}

The studies are generally in favor of bioceramic materials even if currently there are not many products available for endodontic use. They may be used as endodontic cements in root perforations, large apical foramens and root resorptions. As more products will be launched and more research will be performed regarding these materials, we will provide more reliable data on clinical outcomes.

\section{Acknowledgments}

This work was supported by the Romanian Executive Agency for Higher Education, Research, Development and Innovation Funding (UEFISCDI) through grant 241.

\section{References}

1. Cheng L, Ye F, Yang R, Lu X, Shi Y, Li L, et al. Osteoinduction of hydroxyapatite/beta-tricalcium phosphate bioceramics in mice with a fractured fibula. Acta Biomater. 2010;6(4):1569-1574.

2. Hermansson L. Nanostructural bioceramics: Advances in Chemically Bonded Bioceramics. CRC Press 2014.

3. Tomoaia G, Tomoaia-Cotisel M, Pop LB, Mocanu A, Pop A. Nanopowders of hydroxyapatite and its substituted derivatives with medical applications and their fabrication procedure. Romanian Patent A20100523, 10 April, 2013.

4. Estrela C, Bammann LL, Estrela CR, Silva RS, Pécora JD. Antimicrobial and chemical study of MTA, Portland cement, calcium hydroxide paste, Sealapex and Dycal. Braz Dent J. 2000;11:3-9.

5. Funteas UR, Wallace JA, Fochtman EW. A comparative analysis of Mineral Trioxide Aggregate and Portland cement. Aust Endod J. 2003;29:43-44.

6. Oliveira MG, Xavier CB, Demarco FF, Pinheiro AL, Costa AT, Pozza DH. Comparative chemical study of MTA and Portland cements. Braz Dent J. 2007;18(1):3-7.

7. Scheerer SQ, Steiman HR, Cohen J. A comparative evaluation of three root-end filling materials: an in vitro leakage study using Prevotella nigrescens. J Endod. 2001;27:40-42.

8. Camilleri J, Montesin FE, Papaioannou S, McDonald F, Pitt Ford TR. Biocompatibility of two commercial forms of mineral trioxide aggregate. Int Endod J. 2004;37:699-704.

9. Porter ML, Bertó A, Primus CM, Watanabe I. Physical and chemical properties of new-generation endodontic materials. J Endod. 2010;36(3):524-528.

10. Camilleri J. The chemical composition of mineral trioxide aggregate. J Conserv Dent. 2008;11(4):141-143.

11. Camilleri J. Mineral Trioxide Aggregate in Dentistry. Springer 2014.

12. Kossev D, Stefanov V. Ceramic-based sealers as new alternative to currently used endodontic sealers. Available from: http://www. endoexperience.com/documents/Ceramicbasedsealers.PDF

13. Koch K, Brave D, Ali Nasseh A. A review of bioceramic technology in endodontics. Available from: http://www.dentaltribune.com/htdocs/uploads/printarchive/editions/60f01a2ff3964 14f6815530033a55bf8_6-12.pdf

14. Zhu L, Yang J, Zhang J, Peng B. A comparative study of BioAggregate and ProRoot MTA on adhesion, migration, and attachment of human dental pulp cells. J Endod. 2014;40(8):11181123 .

15. Ribeiro CS, Kuteken FA, Hirata Junior R, Scelza MF. Comparative evaluation of antimicrobial action of MTA, calcium hydroxide and Portland cement. J Appl Oral Sci. 2006;14:330333.

16. Ehsani M, Dehghani A, Abesi F, Khafri S, Ghadiri Dehkordi S. Evaluation of Apical Micro-leakage of Different Endodontic Sealers in the Presence and Absence of Moisture. J Dent Res Dent Clin Dent Prospects. 2014;8(3):125-129.

17. Topçuoğlu HS, Arslan H, Akçay M, Saygili G, Cakici F, Topçuoğlu G. The effect of medicaments used in endodontic regeneration technique on the dislocation resistance of mineral trioxide aggregate to root canal dentin. J Endod. 2014;40(12):20412044.

18. Madani ZS, Sefidgar SA, Rashed Mohasel A, Zabihi E, Mesgarani A, Bijani A, et al. Comparative evaluation of antimicrobial activity of two root canal sealers: MTA Fillapex and AH 26. Minerva Stomatol. 2014;63(7-8):267-272.

19. Sipert CR, Hussne RP, Nishiyama CK, Torres SA. In vitro antimicrobial activity of Fill Canal, Sealapex, Mineral Trioxide Aggregate, Portland cement and EndoRez. Int Endod J. 2005;38(8):539-543.

20. Samyuktha V, Ravikumar P, Nagesh B, Ranganathan K, Jayaprakash T, Sayesh V. Cytotoxicity evaluation of root repair materials in human-cultured periodontal ligament fibroblasts. J Conserv Dent. 2014;17(5):467-470.

21. De Deus G, Ximenes R, Gurgel-Filho ED, Plotkowski MC, Coutinho-Filho T. Citotoxicity of MTA and Portland cement on human ECV 304 endothelial cells. Int Endod J. 2005;38:604-609. 22. Holland R, de Souza V, Murata SS, Nery MJ, Bernabé PF, Otoboni Filho JA, et al. Healing process of dog dental pulp after pulpotomy and pulp covering with mineral trioxide aggregate or Portland cement. Braz Dent J. 2001;12:109-113.

23. Al-Hiyasat AS, Barrieshi-Nusair KM, Al-Omari MA. The radiographic outcomes of direct pulp-capping procedures performed by dental students: a retrospective study. J Am Dent Assoc. 2006;137(12):1699-1705.

24. Barthel CR, Rosenkranz B, Leuenberg A, Roulet JF. Pulp capping of carious exposures: treatment outcome after 5 and 10 years: a retrospective study. J Endod. 2000;26(9):525-528.

25. Camilleri J, Pitt Ford TR. Mineral trioxide aggregate: a review of the constituents and biological properties of the material. Int Endod J. 2006;39(10):747-754.

26. Junn DJ. Quantitative assessment of dentin bridge formation following pulp-capping with mineral trioxide aggregate (master's thesis). Loma Linda, Calif.: Loma Linda University; 2000.

27. Moghaddame-Jafari S, Mantellini MG, Botero TM, McDonald NJ, Nör JE. Effect of ProRoot MTA on pulp cell apoptosis and proliferation in vitro. J Endod. 2005;31(5):387-391.

28. Mente J, Hufnagel S, Leo M, Michel A, Gehrig H, Panagidis $\mathrm{D}$, et al. Treatment outcome of mineral trioxide aggregate or calcium hydroxide direct pulp capping: long-term results. J Endod. 2014;40(11):1746-1751. 